\title{
Visualization of Adult Stem Cells Within Their Niches Using the Drosophila Germline as a Model System
}

\author{
Annekatrin König and Halyna R. Shcherbata
}

\begin{abstract}
The germaria of the fruit fly Drosophila melanogaster present an excellent model to study germline stem cell-niche interactions. Two to three adult stem cells are surrounded by a number of somatic cells that form the niche. Here we describe how Drosophilae germaria can be dissected and specifically immunostained to allow for identification and analysis of both the adult stem cells and their somatic niche cells.
\end{abstract}

Key words Drosophila, Germarium, Ovary, Adult stem cells, Stem cell niche, Germline, Ovarian soma, Immunostaining

1 Introduction

Adult stem cells usually reside in the stem cell niche, a unique physiological microenvironment that helps stem cells to carry on self-renewing divisions throughout the lifetime of an organism. The niche includes cellular and noncellular elements that can be divided into one of the two main mechanistic types - physical contacts and diffusible factors [1]. Close contacts include tight junctions, adherens junctions, gap junctions, the Notch signaling pathway, the basement membrane, and extracellular matrix proteins. Diffusible factors, which are secreted by niche cells and travel over varying distances to keep stem cell identity, often affect transcription. Stem cells must be anchored to the niche through cellcell interactions so that they will stay both close to niche factors that specify self-renewal and far from differentiation stimuli.

Presently the existence of a stem cell niche has been demonstrated for mammalian adult stem cells in the hematopoietic, epidermal, neural, and intestinal systems. However, the stem cell niches involved in maintenance of adult mammalian tissues and particularly their role in cancer development remain complex, poorly defined, and difficult to study in vivo [2]. 

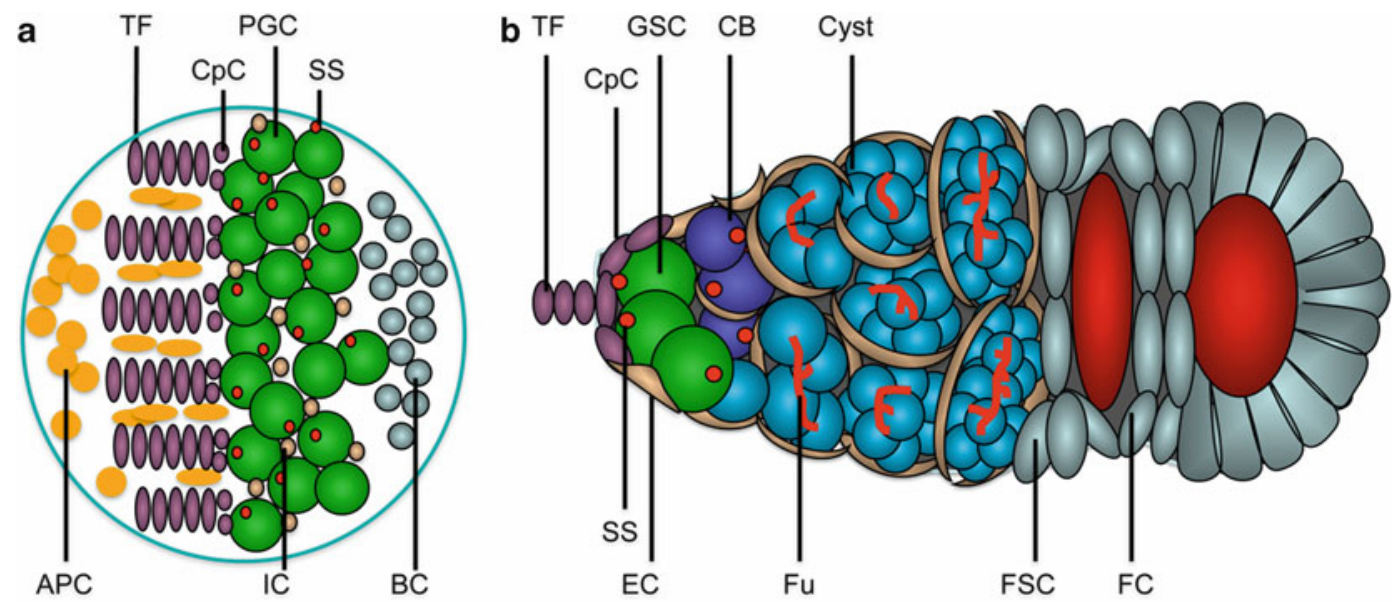

Fig. 1 Scheme of larval ovary and adult germarium. (a) The primordial germ cells (PGC) that can be identified by their characteristic spherical spectrosomes ( $S S$ spherical skeletal organelles) are intermingled with somatic cells (IC, intermingled cells). Stacks of the terminal filament (TF) cells have already formed in late L3 larvae. Cap cells (CpCs) are forming in late L3 larvae through the early pupal stages at the base of TFs. Two populations of somatic cells ( $A P C$, apical cells, $B C$, basal cells) are also found in the larval ovary. (b) In the adult ovaries, the individual ovarioles with the germaria are separated by peritoneal sheath. The germline stem cells (GSCs) are positioned at the anterior of the germarium and directly attached to cap cells. Upon asymmetric division, the stem cells give rise to another stem cell and a differentiating daughter, the cystoblast (CB). The cystoblast divides four more times with incomplete cytokinesis, forming the cyst. During that process, the spherical spectrosomes of the GSCs elongate and branch to form the fusome (Fu). The terminal filament cells are in close proximity to the cap cells, but have a more oval shape. The GSCs are furthermore in contact with another type of somatic cells that presents an important component of the niche: the escort cells (EC). Follicle cells (FC) that are produced by follicle stem cells (FSC) encapsulate the developing egg. Anterior is to the left

The Drosophila ovarian stem cell niche is very well characterized and has been used for many years to unravel the complex stem cellniche interactions. The insights gained from these studies led to a better understanding of how stem cells work: in addition to cell-cell interactions [3] between stem and niche cells, a variety of signaling pathways involved in stem cell control were described [4-13].

The easily identifiable and analyzable cells in the Drosophila germline niches and the sophisticated genetic tools that are available in Drosophila make it an ideal system for studying stem cell-niche interactions [14]. The paired ovaries of the adult female fly each consist of 16-20 ovarioles that contain developing egg chambers. Located at the anterior of every ovariole is the germarium, where two to three stem cells are held by 5-7 cap cells and are in contact with other somatic cells (see Fig. 1b). By asymmetric division, the adult stem cells give rise to both new stem cells and differentiated cells that will become the egg. The differentiated germline cells are surrounded by somatic escort cells that are another important component of the stem cell niche $[4,15]$. More posteriorly, follicle cells that are generated by specific stem cells encapsulate the differentiating germline [16]. The individual ovarioles are held together by the 


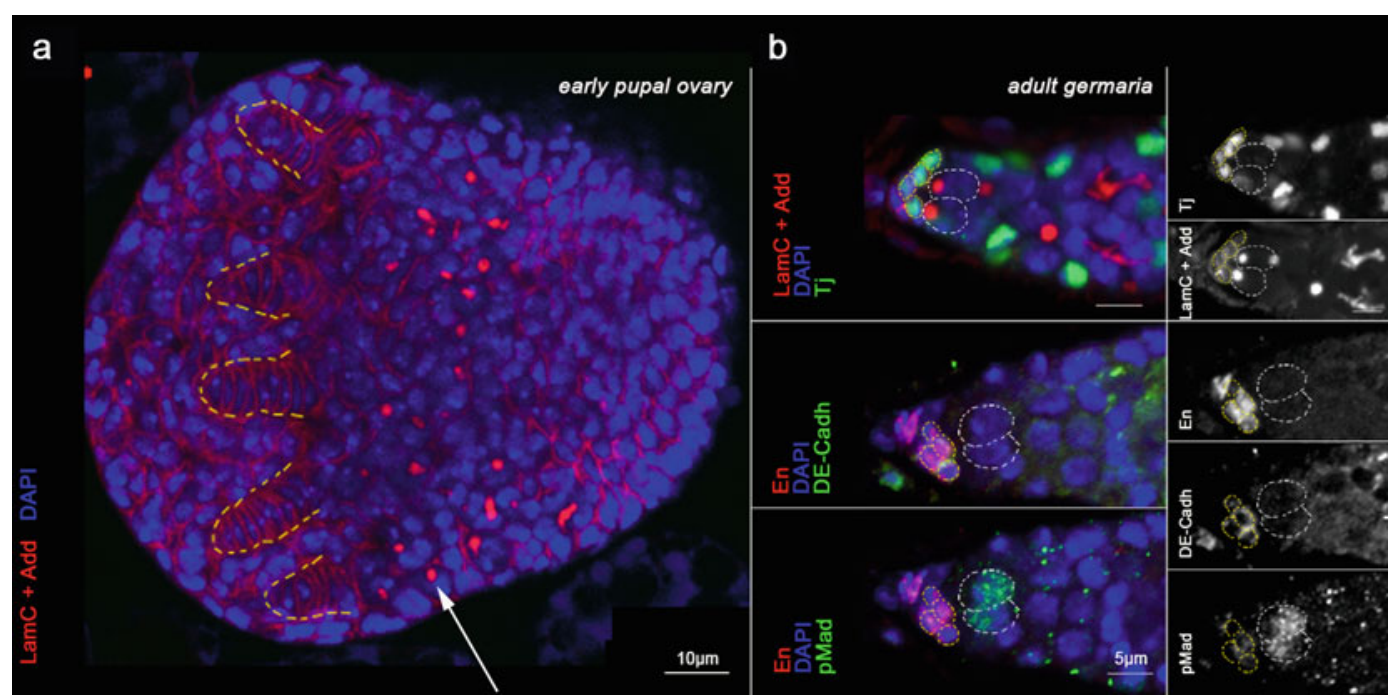

Fig. 2 Pre-adult ovary and adult germaria. (a) In the late larval and early pupal ovaries, terminal filament stacks become visible (outlined in yellow). The PGCs (arrow), that can be identified by their spherical SSs, are not separated yet into individual ovarioles and intermingled with somatic cells. (b) Adult ovaries consist of several germaria, each containing 2-3 GSCs, that can be not only identified by their characteristic Adducin-marked SSs but also stained with the stem cell marker pMad. Directly attached to the stem cells are several somatic cells that are forming the stem cell niche: the CpCs can be marked using LaminC or Engrailed. DE-Cadherin staining shows the adhesion contacts between the GSCs and CpCs. Furthermore, ECs and CpCs are marked here with Traffic jam

terminal filaments. A variety of different markers makes it possible to nicely immunostain and analyze number, localization, shape, and interactions of the individual cells (see Fig. 2b). In addition, the development of the stem cell niche itself can be directly observed in developing larvae and early pupae where the cap cells divide and terminally differentiate (see Figs. la and 2b) [17].

In this chapter we show how to visualize adult stem cells in their niches in adult female Drosophila.

\section{Materials}

\subsection{Fly Husbandry}

1. Standard cornmeal agar food (recipes can be found at http:// fly.bio.indiana.edu/).

2. Yeast paste: Dry yeast should be mixed in $5 \%$ propionic acid (see Note 1).

\subsection{Ovary Dissection $\quad$ 1. Ice block for immobilization of the flies.}

2. Sharp tweezers.

3. Small Petri dish for dissections.

4. Stereomicroscope for dissection.

5. Pasteur pipettes. 


\subsection{Fixation and Washing}

2.4 Antibodies
1. Fixing solution: $4 \%$ formaldehyde in phosphate-buffered saline (PBS) (see Note 2).

2. Nutator.

3. PBT: $0.2 \%$ Triton $\mathrm{X}$ in PBS.

1. Blocking solution: $0.2 \%$ bovine serum albumin, $5 \%$ normal goat serum in PBT (see Note 3 ).

2. Primary antibodies: Many antibodies are available to study germline-niche interactions; some of these are listed in Table 1. Dilute primary antibodies in blocking solution and store at $4{ }^{\circ} \mathrm{C}$ ( see Notes 4-8).

\section{Table 1}

A subset of antibodies that are useful to study germline stem cell niche interactions is shown

\begin{tabular}{|c|c|c|c|c|c|}
\hline Protein recognized & $\begin{array}{l}\text { Name of the } \\
\text { antibody }\end{array}$ & Raised in & $\begin{array}{l}\text { Antibody } \\
\text { source }\end{array}$ & $\begin{array}{l}\text { Used to mark in the } \\
\text { germarium }\end{array}$ & Dilution \\
\hline Armadillo & N2 7Al & $\begin{array}{l}\text { Mouse, } \\
\quad \operatorname{IgG} 2 \mathrm{a}\end{array}$ & DSHB Iowa & $\begin{array}{l}\text { Cell-Cell adhesion } \\
\text { between cap cells } \\
\text { and between stem } \\
\text { cells and cap cells }\end{array}$ & $1: 50$ \\
\hline $\begin{array}{l}\text { Bag of marbles } \\
\text { (BAM) }\end{array}$ & $\begin{array}{l}\text { BamC } \\
\text { (cyto- } \\
\text { plasmic) }\end{array}$ & Mouse, Rat & D. McKearin & $\begin{array}{l}\text { Differentiating } \\
\text { germline cysts, not } \\
\text { in germline stem cells }\end{array}$ & $1: 1,000$ \\
\hline $\begin{array}{l}\text { E-Cadherin, } \\
\text { extracellular } \\
\text { domain }\end{array}$ & $5 \mathrm{D} 3$ & $\begin{array}{l}\text { Mouse, } \\
\quad \text { IgG2b }\end{array}$ & $\begin{array}{l}\text { DSHB } \\
\text { Iowa }\end{array}$ & $\begin{array}{l}\text { Cell-Cell adhesion } \\
\text { between cap cells } \\
\text { and between stem } \\
\text { cells and cap cells }\end{array}$ & $1: 50$ \\
\hline Engrailed & 4D9 & $\begin{array}{r}\text { Mouse, } \\
\text { IgGl }\end{array}$ & $\begin{array}{l}\text { DSHB } \\
\text { Iowa }\end{array}$ & Cap cells & $1: 50$ \\
\hline $\begin{array}{l}\text { Held out wings } \\
\text { (HOW) }\end{array}$ & HOW & $\begin{array}{c}\text { Rabbit, } \\
\text { Rat }\end{array}$ & T. Volk & $\begin{array}{l}\text { Germline stem cells, } \\
\text { cystoblasts }\end{array}$ & $1: 1,000$ \\
\hline Hts/Adducin-like & 1B1 & $\begin{array}{r}\text { Mouse, } \\
\text { IgGl }\end{array}$ & $\begin{array}{l}\text { DSHB } \\
\text { Iowa }\end{array}$ & $\begin{array}{l}\text { Spectrosomes } \\
\text { and fusomes }\end{array}$ & $1: 50$ \\
\hline Lamin C & LC28.26 & Mouse, IgGl & $\begin{array}{l}\text { DSHB } \\
\text { Iowa }\end{array}$ & Cap cells & $1: 50$ \\
\hline $\begin{array}{l}\text { Phosphorylated } \\
\text { Mothers against } \\
\text { Dpp (pMAD) }\end{array}$ & pMad & Rabbit & E. Laufer & Germline stem cells & $1: 5,000$ \\
\hline Traffic jam & TJ & Guinea pig & D. Godt & Escort cells, cap cells & $1: 3,000$ \\
\hline Vasa & & Rat & P. Lasko & Germline cells & $1: 1,000$ \\
\hline
\end{tabular}

Scientists who generated a particular antibody are named as source. Their addresses are available from flybase (http:// flybase.org/). DSHB Developmental Studies Hybridoma Bank at the University of Iowa 
3. Secondary antibodies: Conjugated Alexa fluor goat antimouse, goat anti-rabbit, or goat anti-rat from Molecular Probes, diluted 1:500 in blocking solution (Molecular Probes); store at $4{ }^{\circ} \mathrm{C}$ ( see Notes 8 and 9 ). The secondary antibodies have to be chosen with respect to the laser lines of the available microscope.

\subsection{DNA Staining and Mounting}

2.6 Analysis

3 Methods

3.1 Dissection

3.1.1 Adult Ovaries

3.1.2 Larval Ovaries
1. DAPI solution: Make a $100 \times$ DAPI solution $(1 \mathrm{mg} / \mathrm{ml})$ and store aliquots at $-20{ }^{\circ} \mathrm{C}$. For staining, dilute in PBS (see Note 10).

2. Glycerol: $70 \%$ Glycerol, $3 \%$ n-propyl gallate (NPG) (see Note 11).

3. Tungsten needles.

Laser scanning confocal microscope is used for analysis.

All steps are carried out at room temperature unless otherwise stated. During all incubations and washes, the Eppendorf tubes are placed on a nutator.

1. Immobilize 5-10 female flies by putting them on an ice block.

2. The ovaries are positioned in the abdomen of the fly and are simple to find in well-fed individuals ( see Note 12). Dissect the flies in $1 \times$ PBS using a stereomicroscope, and hold the fly with one pair of tweezers at the thorax. Carefully open the cuticle at the posterior end of the animal with another pair of tweezers. If necessary, gently push the abdomen to squeeze out the paired ovaries. Remove all remnants of guts and cuticle and place the ovaries in an Eppendorf tube using Pasteur pipettes (see Note 13).

1. Pick up late third instar larvae from the wall of the food vial or bottle.

2. Select a female larva and hold with a pair of tweezers at the anterior end.

3. The larval ovaries are located in the fat body. Cut off the larval head and hold the posterior end of the remaining larval body with one pair of tweezers. Carefully now invert the larvae by pulling it over the tweezers with another pair of tweezers. Remove cuticle and guts and transfer the fat body into an Eppendorf tube or a 24-well plate (see Note 14). 
3.1.3 Fixation

\subsection{Antibody} Staining
1. Add fixing solution and incubate for $10 \mathrm{~min}$. Remove the fixing solution carefully and wear protective gloves when handling the fixative.

2. Wash the ovaries three times for 15 min each with PBT (see Notes 15 and 16).

1. Add blocking solution and incubate for $\mathrm{l} \mathrm{h}$.

2. Remove the blocking solution and add primary antibody solution. Incubate overnight at $4{ }^{\circ} \mathrm{C}$.

3. Remove the antibody solution (see Note 5) and wash the ovaries three times for 15 min each with PBT.

4. Block again in blocking solution for $\mathrm{l} \mathrm{h}$.

5. Incubate the ovaries in secondary antibody solution overnight at $4{ }^{\circ} \mathrm{C}$ or for $3 \mathrm{~h}$ at room temperature.

6. Remove the secondary antibody solution and wash with PBT twice for $15 \mathrm{~min}$. Add DAPI solution and incubate for $10 \mathrm{~min}$.

7. Remove the DAPI solution and wash three times for $15 \mathrm{~min}$ with PBT.

8. Remove as much PBT as possible and add a few drops of glycerol to the ovaries.

(a) Adult ovaries: Place the ovaries on a slide and use tweezers and tungsten needles to separate the individual ovaries and to remove the mature eggs.

(b) Larval ovaries: Place the fat bodies on a slide and locate the larval ovaries. Carefully remove remnants of the fat body.

9. Place a coverslip on top of the samples and analyze using a confocal microscope.

1. The yeast paste should have a "peanut butter-like" texture. The propionic acid helps to avoid fungal or bacterial contamination.

2. Prepare the solution fresh from a $16 \%$ stock solution at room temperature.

3. Goat serum is used in the blocking solution if the secondary antibody was produced in goat. If you have to use secondary antibodies that were generated in another animal, use other serums from the appropriate animal.

4. Primary antibodies: Apart from several monoclonal antibodies, that are available from the Developmental Studies Hybridoma Bank, a variety of different polyclonal rabbit, goat, sheep, and 
guinea pig antibodies have been made by different labs (see Table 1). However, make sure not to use goat serum in the blocking solution if the primary antibody is goat derived.

5. When analyzing GFP-marked clonal cells, you may use an antiGFP antibody to better visualize the GFP.

6. Stability of primary antibodies: Some primary antibodies can be reused a couple of times, whereas others can be used only once. Dilution and stability of every antibody or antibody batch have to be tested separately.

7. If the antibody staining shows a high level of nonspecific background, it may be pre-absorbed with fixed embryos: incubate fixed embryos overnight with the antibody solution. Use this antibody solution and use it for staining your sample.

8. To avoid bacterial contamination and to extend stability of the antibody solution $0.05 \%$ of sodium azide can be added.

9. Choose an antibody that targets the animal in which the primary antibody was produced. Conjugated Alexa fluor antibodies that were raised to target different animals and that have sufficiently different emission spectra can be combined to immunostain different antigens at a time. Additionally, if the primary antibodies are from different antibody subclasses ( $\operatorname{IgM}$ or IgG subclasses) secondary antibodies specific to the antibody subclass can be used to discriminate the patterns. Sensitivity and/or cross-reactivity can vary. We have had good experiences with Alexa 568 goat anti-mouse (emits red light), combined with for example Alexa 488 goat anti-rabbit/rat (emits green light) and Alexa 633 goat anti-rat/rabbit (emits far-red light).

10. If the available confocal microscope does not have a UV laser illumination system that is necessary to detect DAPI-stained DNA, you may use propidium iodide to stain the nuclei instead. Propidium iodide staining: Incubate the ovaries for $15 \mathrm{~min}$ in PBS containing $2 \mu \mathrm{gf} / \mathrm{ml}$ propidium iodide. Staining with DAPI allows you to use three other secondary antibodies emitting green, red, and far-red light in parallel with DNA staining, whereas propidium iodide emits red light itself.

11. Add NPG to the glycerol and vortex. If the NPG will not dissolve, heat the solution at $37^{\circ} \mathrm{C}$ overnight.

12. Oogenesis is highly dependent on the individual's environment. Therefore, the flies should be "fattened" on wet yeast prior to dissection for at least 2 days and should also be kept in a community with males. However, when analyzing ovarian phenotypes it is recommended to collect and stain wild-type and mutant females at different timepoints and in several independent experiments. 
13. Depending on the antibody used, the immunostaining protocol can vary. If the used antibody is also staining the peritoneal muscle sheath, it is necessary to destroy the sheath around the ovarioles by sucking them up and down several times in a Pasteur pipette.

14. The larval fat body that contains the ovaries will not sink to the ground, but floats in the solution. It is therefore recommended to check under the stereomicroscope that the fat bodies are not washed away when adding or removing liquids from the sample.

15. The ovaries should be fixed as fast as possible after dissection to preserve the cellular structures. It is important not to exceed or shorten the fixation time to avoid poor immunostaining.

16. Upon all incubation and washing steps make sure to add an amount of liquid that is sufficient to allow the ovaries to float in the tube or the plate upon gentle rocking. Furthermore, when removing solutions from the tube do not pull up the ovaries into the pipette and do not damage the ovaries. The ovaries should stay intact until the very end of the procedure since the individual germaria are otherwise very easily lost.

\section{References}

1. Walker MR, Patel KK, Stappenbeck TS (2009) The stem cell niche. J Pathol 217(2):169-180. doi:10.1002/path.2474

2. Scadden DT (2006) The stem-cell niche as an entity of action. Nature 441(7097): 1075-1079. doi:10.1038/nature04957

3. Song X, Zhu CH, Doan C, Xie T (2002) Germline stem cells anchored by adherens junctions in the Drosophila ovary niches. Science 296(5574):1855-1857. doi:10.1126/ science. 1069871

4. Decotto E, Spradling AC (2005) The Drosophila ovarian and testis stem cell niches: similar somatic stem cells and signals. Dev Cell 9(4):501-510. doi:10.1016/j.devcel.2005.08.012

5. Xie T, Spradling AC (1998) Decapentaplegic is essential for the maintenance and division of germline stem cells in the Drosophila ovary. Cell 94(2):251-260

6. Yu JY, Reynolds SH, Hatfield SD, Shcherbata HR, Fischer KA, Ward EJ, Long D, Ding Y, Ruohola-Baker H (2009) Dicer-1-dependent Dacapo suppression acts downstream of Insulin receptor in regulating cell division of Drosophila germline stem cells. 2009 136(9):1497-507. doi:10.1242/dev.025999
7. McKearin D, Ohlstein B (1995) A role for the Drosophila bag-of-marbles protein in the differentiation of cystoblasts from germline stem cells. Development 121(9):2937-2947

8. Song X, Wong MD, Kawase E, Xi R, Ding BC, McCarthy JJ, Xie T (2004) Bmp signals from niche cells directly repress transcription of a differentiation-promoting gene, bag of marbles, in germline stem cells in the Drosophila ovary. Development 131(6):1353-1364. doi:10.1242/dev.01026

9. Konig A, Yatsenko AS, Weiss M, Shcherbata HR (2011) Ecdysteroids affect Drosophila ovarian stem cell niche formation and early germline differentiation. EMBO J 30(8): 1549-1562. doi:10.1038/emboj.2011.73

10. Shcherbata HR, Ward EJ, Fischer KA, Yu JY, Reynolds SH, Chen $\mathrm{CH}$, Xu P, Hay BA, Ruohola-Baker H (2007) Stage-specific differences in the requirements for germline stem cell maintenance in the Drosophila ovary. Cell Stem Cell. 1(6):698-709. doi:10.1016/j.stem. 2007.11.007

11. Hatfield SD, Shcherbata HR, Fischer KA, Nakahara K, Carthew RW, Ruohola-Baker H (2005) Stem cell division is regulated by the 
microRNA pathway. Nature 435(7044): 974-978. doi:10.1038/nature03816

12. Ward EJ, Shcherbata HR, Reynolds SH, Fischer KA, Hatfield SD, Ruohola-Baker H (2006) Stem cells signal to the niche through the Notch pathway in the Drosophila ovary. Curr Biol 16(23):2352-2358. doi:10.1016/j. cub.2006.10.022

13. Wang L, Li Z, Cai Y (2008) The JAK/STAT pathway positively regulates DPP signaling in the Drosophila germline stem cell niche. J Cell Biol 180(4):721-728. doi:10.1083/ jcb.200711022

14. Losick VP, Morris LX, Fox DT, Spradling A (2011) Drosophila stem cell niches: a decade of discovery suggests a unified view of stem cell regulation. Dev Cell 21(1):159-171. doi:10.1016/j.devcel.2011.06.018

15. Kirilly D, Wang S, Xie T (2011) Self-maintained escort cells form a germline stem cell differentiation niche. Development 138(23):5087-5097. doi:10.1242/dev.067850

16. Margolis J, Spradling A (1995) Identification and behavior of epithelial stem cells in the Drosophila ovary. Development 121(11): 3797-3807

17. Gilboa L, Lehmann R (2006) Soma-germline interactions coordinate homeostasis and growth in the Drosophila gonad. Nature 443(7107): 97-100. doi:10.1038/nature05068 